\title{
Speed perception by drivers as dependent on urban street design; a case-study
}

\author{
Victoria Gitelman, Fany Pesahov, Roby Carmel \\ Transportation Research Institute, Technion City, Haifa, Israel 32000
}

ABSTRACT: The strategy of sustainable road safety aims to match the road design characteristics to the target travel speeds, on every road type. This study examined the speed perception by drivers on collector urban roads in Israel, as reflected in their actual travel speeds and in the "appropriate" speeds reported by drivers. First, field surveys were conducted to collect detailed data on the road design characteristics, travel speeds, vehicle traffic and pedestrian activities on 80 urban street sections, in fifteen cities. Second, a drivers' survey was undertaken in proximity to the areas of the field surveys, to collect drivers' opinions about appropriate speeds on various street sections. The survey included 200 drivers, where each participant estimated four pictures with representative layouts of the study streets. Multivariate regression models were developed to examine the relationship between street characteristics, traffic exposure and travel speeds, as well as to explore the relationship between the driver characteristics, street design and "appropriate" speeds as reported by drivers. The results showed that road layout type was the most influential on selecting speeds. Multi-lane dual-carriageway roads are characterized by the highest actual and reported speeds, lower speeds are attributed to singlelane dual-carriageway and single-carriageway roads, and the lowest ones - to one-way streets. Among other characteristics moderating actual travel speeds were: higher pedestrian activity on the street, higher visual narrowing, more pedestrian attractions, presence of non-signalized junctions. The selection of "appropriate" speeds by drivers was affected by the street layout, the road visual narrowing, the socio-economic level of the town and driver's personal characteristics. The drivers believed that for moderate street layouts, the appropriate speeds should be around $40 \mathrm{~km} / \mathrm{h}$, i.e. below the existing speed limit. The road design characteristics that were found to affect the speed selection by the drivers may be applicable for attaining targeted travel speeds on collector streets.
KEYWORDS: Speeds; urban collector roads; driver perception; street design

\section{INTRODUCTION}

Speed was proven to be a crucial factor in accident occurrences and their consequences (Aarts and van Schagen, 2006; Elvik et al., 2019). Thus, great importance is assigned to speed management of the road system to improve its safety and mobility (OECD, 2006; European Commission, 2018). Speed surveys conducted in other countries and in Israel showed that the problem of traveling at higher speeds than the speed limits is prevalent on various road types (Gitelman, 2014; Adminaité-Fodor and Jost, 2019). The high percentage of drivers traveling at high speeds may be explained, in certain cases, by a "contradiction" between the road characteristics and the posted speed limits. In urban areas, lower speed limits are sometimes posted due to the presence of vulnerable road users. However, when the road layout is not fitted to such speed limits, the actual speeds are higher and the use of infrastructure measures moderating travel speeds is required (OECD, 2006; European Commission, 2018).

The strategy of sustainable road safety is gradually expanding in the world over the last decade (Weijermars and Wegman, 2011; Breen, 2018); recently, it was generalized in the paradigm of a Safe System approach (ITF, 2016). With regard to travel speeds, one of the management tools is seen in the use of engineering measures for improving existing road infrastructure and constructing new roads, so that the design characteristics of the road should deliver a clear message to drivers on the speeds appropriate for traveling on each road section (OECD, 2006; ITF, 2016). To attain this, each road type has to obtain a clearly defined function that is reflected in the road 
design. This approach is closely related to the concept of "self-explaining roads" that was introduced in the literature several decades ago (e.g. Van der Horst and Kaptein, 1996). The affinity of both concepts was exhibited particularly in the development of sustainable road safety strategy in the Netherlands that promoted the principles of mono-functionality of the road types on the network, predictability of the road environment and recognizable road design (Weijermars and Wegman, 2011).

In Israel, the guidelines for setting speeds on the road network were introduced (Ministry of Transport, 2010) aiming to create a road system which would have a balance between the intention of the authorities and engineers who built the roads and the behaviors of drivers who travel on those roads. Such a balance is achieved when there is a match between the target speed of a particular road type and the actual travel speeds selected by the drivers. The guidelines defined a new hierarchy of the road types with their target and design speeds. However, there is still a need for the design tools that may help in implementing the new approach - matching road infrastructure characteristics to the designated speeds, on each road type. It is important to identify those design features, which are understood by drivers and, thus, may be appropriate to "explain" the target travel speed. In this context, empirical knowledge may be useful with regard to drivers' perception of existing road characteristics, under the local conditions.

Among urban roads in Israel, the major problem of traveling above the speed limit was observed on collector streets, which have $50 \mathrm{~km} / \mathrm{h}$ speed limits (Gitelman, 2014; Troitsky, 2018). Such streets are characterized by mixed land uses, significant vehicle traffic volumes and high pedestrian activities, and are frequently associated with road safety problems and, particularly, pedestrian accidents, in urban areas (Gitelman et al., 2012; 2018). Thus, this study focused on the relationship between road design characteristics and travel speeds, on collector urban roads in Israel. The study aimed to explore how urban road characteristics are perceived by drivers, whereas "the perception" is reflected in actual travel speeds and in choosing the speeds "appropriate", according to drivers' opinions, to each road section.

\subsection{Previous research}

Previous research indicated that travel speed choice of a driver is affected by the driver's personal char- acteristics, experience and attitudes but also by objective factors such as driving environment, road and traffic conditions (Eiksund, 2009; Shinar, 2017; European Commission, 2018). Therefore, a driver's behavior can be influenced directly by engineering measures applied on urban and other roads. Previous studies showed that road design characteristics affect travel speeds chosen by drivers, on various road types (Edquist et al., 2009; Ivan et al., 2009; European Commission, 2018) and, conversely, that travel speeds are suitable to serve as an objective measure of drivers' perception of various road conditions (Weller et al., 2008; Charlton et al., 2010; Gitelman et al., 2016).

For example, Ivan et al. (2009), in a study of urban, suburban and non-urban locations in Connecticut, found that higher travel speeds were associated with wide shoulders, far setback of buildings from the roadway and residential areas' environment, while lower travel speeds - with on-street parking, presence of sidewalks and downtown or commercial areas. It was concluded that drivers slow down where the road is visually constricted or there are noticeable onstreet activities, but they speed up where the road is perceived as "open" or on-street activities are scarce. Thus, by selection of road and environment features, it is possible to influence the street travel speeds.

In England, based on the data from twenty urban sites, York et al. (2007) found that travel speeds, both on road sections and near intersections, rise under better visibility conditions and with the roadway width expansion. Conversely, narrower roadways, presence of street parking and the vicinity of junctions were associated with a reduction in travel speeds. A study conducted in Auckland, New Zealand (Charlton et al., 2010), examined the impact on travel speeds of road infrastructure changes in a treatment versus control area. It showed that an extensive application of changes in road delineation and landscaping, with narrowing traffic lanes and underlining bicycle and pedestrian facilities, attains a reduction in travel speeds on both local and collector roads, and this without changes in speed limits or enforcement.

In Italy, Bassani et al. (2014) examined the impact of road design characteristics on operating speeds of vehicles which were measured on urban arterials and collector streets, in Torino. They found that lane position in the road layout and the number of traveled ways were the most influential variables on the mean value of the observed speeds. In addition, many 
longitudinal and transversal road geometric characteristics, e.g. presence and width of shoulders, presence of dedicated bus lanes, sidewalks and pedestrian crossing, traffic calming devices, were found to affect the speed dispersion.

Summarizing previous research findings with regards to urban roads, among road characteristics associated with lower travel speeds can be mentioned: lower posted speed limits and higher density of signalized intersections (Fitzpatrick et al., 2005); narrow roadways or traffic lanes (York et al., 2007; Edquist et al., 2009; Charlton et al., 2010; Bassani et al., 2014); traffic calming measures (Edquist et al., 2009; York et al., 2007; European Commission, 2018); pedestrian activity or presence of pedestrian settings on the street (Fitzpatrick et al., 2005; Ivan et al., 2009; Bassani et al., 2014); presence of parking lanes (Fitzpatrick et al., 2005; York et al., 2007); presence of bicycle or bus lanes (Milot, 2008); reduced forward visibility (York et al., 2007; Edquist et al., 2009; Charlton et al., 2010); side visual narrowing or the proximity of buildings to the road (Milot, 2008; Ivan et al., 2009). However, the relationship between the road characteristics and actual travel speeds is not complete yet to provide a basis for future road design, particularly with regard to collector roads. Besides, differences are evident in the composition of characteristics that were explored and those found as influential on travel speeds, by various studies. Thus, additional empirical studies may be useful to improve understanding of this relationship. The current study focused on exploring such a relationship, on collector urban roads, under Israeli conditions.

\section{METHODOLOGY}

The study had two main components. First, field surveys were conducted to collect the information on road design characteristics, travel speeds, vehicle and pedestrian volumes on the collector streets, throughout the country. This database was used for the examination of relationships between actual travel speeds and other street characteristics. Second, a driver survey was undertaken to examine drivers' attitudes towards appropriate speeds on various street sections, with consequent analyses to identify road and driver characteristics that are related to the drivers' perception of the appropriate speeds.

\subsection{Field surveys: data collection and analyses}

According to the street design guidelines (Guidelines, 2009), in the urban road network, collector streets are intended to provide a connection between arterial

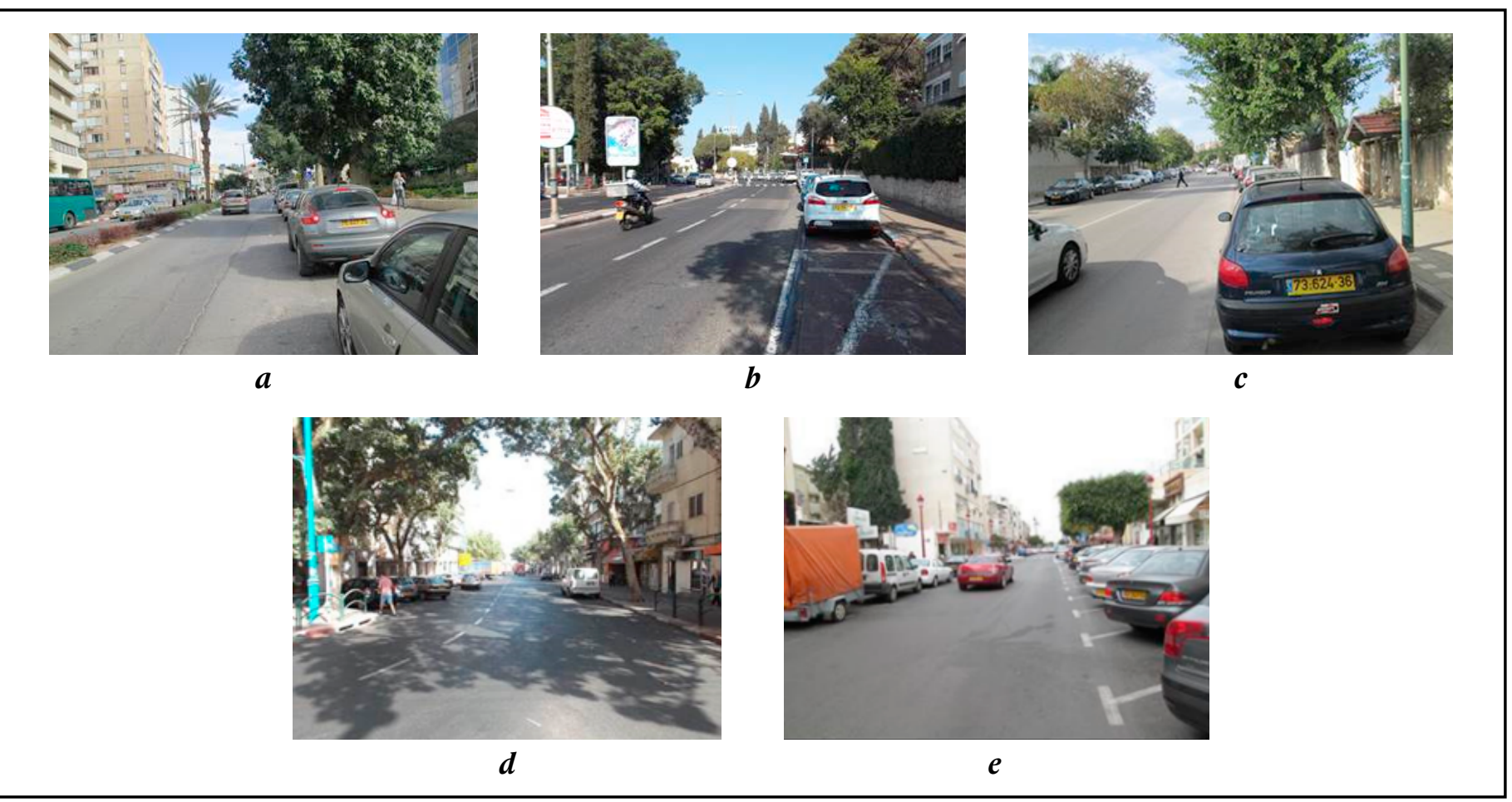

Figure 1. Examples of road layouts: a - single-lane dual-carriageway, $b$ - multi-lane dual-carriageway, $c$ - two-way singlecarriageway, $d$-two-lane one-way, $e$ - one-lane one-way road. 
roads and local streets. Such streets present a mixture of functions, as they should serve passing traffic, on the one hand, and satisfy access needs, on the other. As a result, they are usually characterized by mixed land uses, high traffic volumes and pedestrian activities, and are situated in city centers and on the boundaries of residential areas. The collector streets for the study were selected in the medium- and largesized Israeli cities, with a population over 30,000 inhabitants; smaller towns were excluded because collector roads with high traffic volumes and mixed land uses are not common in such towns. In addition, an examination of accidents showed that towns of the size selected for the study comprised $92 \%-94 \%$ of the total injury and pedestrian accident locations.

Concerning the road layout, the collector streets in Israel can be of five types such as: single-lane dualcarriageway, multi-lane dual-carriageway, two-way single-carriageway, two-lane one-way and one-lane one-way roads; examples of streets with various layouts are presented in Figure 1. All these types were included in the study. Detailed information on each street was collected during a field survey, which covered 15 cities.

A uniform time framework was defined for the data collection at all sites: working days, between hours 10-13 in the morning, i.e. during the hours of major urban activities (after morning congestion and before afternoon breaks of offices and shops). Due to high changeability of collector street layouts, with a frequent junction appearance, street sections of about $200 \mathrm{~m}$ in length were selected as the study units; some of them were the entire sections between two intersections, others - parts of the street sections adjacent to junctions on one side.

Following previous research (Fitzpatrick et al., 2005; York et al., 2007; Milot, 2008; Edquist et al., 2009; Charlton et al., 2010), with regard to road characteristics, for each study unit, the information was collected concerning:

- The type of road layout, according to five categories as introduced above;

- Lane width, according to three categories: wide (above $3.3 \mathrm{~m}$ ), medium (3.0-3.3 m), small (up to $3.0 \mathrm{~m}$ );

- Presence of visual narrowing, based on the proximity of high obstacles (trees, buildings) to the roadway and median's transparency (if present); divided in five categories, when " 1 " means "no" and "5" - full narrowing;
- Presence of pedestrian attractions, based on the relative share of the commercial frontage on the street; divided in five categories, when " 1 " means "residential only" and " 5 " - 100\% of commercial frontage;

- Visibility distance for vehicles (to reflect the presence of road curvature), divided in three categories, when " 1 " is full visibility (for $200 \mathrm{~m}$ or more), "2" - moderate (between 50-200 m), “3” - short (up to $50 \mathrm{~m}$, a curved street);

- Parking configuration along the street, according to categories: " 0 ” - no parking, “ 1 " - parallel parking, on one side, "2" - diagonal parking, on one side, “3” - parallel, on both sides, " 4 " - parallel on one side and diagonal on the other side; " 5 " - diagonal, on both sides;

- Presence of bus stops - yes/no;

- Presence of pedestrian crosswalks on the street section - yes/no (crosswalks at the intersections are not counted as they are always present);

- Types of intersections at the section ends (signalized, un-signalized, roundabout).

Sidewalks were present on all the streets and thus not indicated. Streets with bicycle lanes and bus lanes were not included in the pool as they were not common yet in Israeli towns.

On each street, free-flow travel speeds were measured with a speed gun, for 30 vehicles, and speed indicators were estimated such as: mean speed, $85^{\text {th }}$ percentile speed and the percentage of drivers traveling above the speed limit $(50 \mathrm{~km} / \mathrm{h})$. To estimate the levels of traffic exposure and pedestrian activity on the street we measured: vehicle traffic, in both directions together; the number of pedestrians passing on the sidewalks; the number of pedestrians that crossed the road at the arranged crosswalks and without crosswalks. Each value was counted twice, for five minutes, and then converted into an average hourly estimate.

To examine the relationship between the road and traffic characteristics of the street sections and the actual travel speeds multivariate regression models were adjusted to the data. First, an exploratory analysis was conducted to select the number of road layout types and the number of exposure indicators, for model development. This was done by means of fitting several regression models, using the whole set of the variables and various compositions of the indica- 
tors examined, and a comparison between the models in terms of the quality of fit and significant variables found. Second, the preferred compositions of the indicators were applied, together with other road characteristics, for the development of explanatory models for the travel speeds. Third, a reduced number of characteristics was used for the development of the explanatory model, i.e. not including the data on the total traffic volumes and on road layouts; this step intended to explore the impacts of other street characteristics (rather than exposure or road layouts) on actual travel speeds. To develop the explanatory models, a hierarchical linear regression with a stepwise method was applied, in the SPSS v.21 software (Raudenbush, 2004). The model fitting stops when a maximum value of the variance explained (adjusted $R$ square) is attained and the F-test is significant.

\subsection{Drivers' opinion survey: the framework for data collection and analyses}

The drivers' survey intended to examine drivers' attitudes on speeds "appropriate" for travel on various collector streets. The opinion survey was conducted through short face-to-face interviews with vehicle drivers, on the streets, in close proximity to the areas where the field surveys took place. The drivers' survey took place at ten sites, in various cities, where at each site the opinions of 20 drivers were collected and each respondent provided his/her judgement with regard to appropriate speeds on four street sections that were presented by pictures. This way, a sample of 800 "driver perceptions" of the street sections was collected. The survey took place near gas stations and open shopping malls, on working days and hours, between 10-17.

Selecting cities for the opinion survey we accounted for the locations of the study's field surveys. Besides, to make the survey representative for the general drivers' population of the country, the cities selected for the survey repeated the composition of the socio-economic levels in the general drivers' population as reflected in the socio-economic clusters of cities of their residence (CBS, 2011).

The driver's perception of speed may be influenced by both personal and objective (road) characteristics (Eiksund, 2009; Shinar, 2017). Thus, the questionnaire designed for the study included background information of the respondent and a visual presentation of the streets to be evaluated. The background information of the respondent included: age group, gender, driving experience (in years), an estimate of annual kilometers traveled, familiarity with the area or the purpose of visit to the city (e.g. lives in the area, works in the area, other), vehicle type (private or other). In addition, in line with previous studies on speed perception, e.g. Lahausse et al. (2010), a set of safety-related statements was suggested to each respondent, to explore their attitudes with regard to the manner of travel in the city. To keep the interview short, only five statements were suggested, as follows:

- In city center I always drive at speed below $50 \mathrm{~km} / \mathrm{h}$

- On street with many crossing pedestrians I slow down

- On street with many parked vehicles I slow down

- On street with signalized junctions I speed up

- On street with many travel lanes I speed up

For the judgement, a "1-5" scale of agreement was applied, where " 1 " corresponds to full disagreement and " 5 " to full agreement with the statement (" 3 " indicates a neutral response). Such a scale is common in opinion surveys (e.g. Preston, Colman, 2000).

Concerning each street shown by a picture, the driver was requested to judge the speed limit and the travel speed "appropriate" for such a street. For the opinion survey, a stock of street pictures with representative road layouts was prepared, based on the street pictures collected during the field surveys. In this process, for each major type of the road layout that was defined in the study (namely, single-lane dual-carriageway, multi-lane dual-carriageway, single-carriageway and one-way), 3-4 representative layouts were suggested using additional road characteristics, e.g. lane width, parking type, presence of visual narrowing on the street. In total, fifteen representative layouts were defined and the pictures of various streets (from the field surveys) were classified, respectively. For the presentation to drivers at each survey site, four sets of four pictures were prepared, with various combinations of the representative road layouts, but always keeping the four major layout types in each set. (During the interview, one of the four sets was randomly selected to be shown to a driver.)

For the analyses, the driver survey responses were converted into the data on street sections. For each street section, the data included speed limits and the 
appropriate speeds as reported by drivers, respondent characteristics from the driver survey and road characteristics, which came from the field surveys. Based on the drivers' responses to the set of safety statements of the questionnaire, we applied a cluster analysis in order to recognize homogeneous groups of drivers according to their attitudes (as to the manner of travel in the city). Using Euclidian distances between the subjects, a Ward dendrogram for the subject classification and a $k$-means method for selecting the number of groups (Johnson \& Wichern, 2002), three groups of drivers with similar attitudes were identified. Belonging to various driver groups was added to the respondent characteristics.

Using the data collected, first, the differences between the reported speed limits and appropriate speeds were examined across various layout types, by means of a paired samples' test. Furthermore, a multivariate analysis of the survey data was performed, in order to fit explanatory models for a relationship between the driver and street characteristics and speeds appropriate for travel on the streets, according to the drivers' opinions. A multiple linear regression with a stepwise method was applied, in the SPSS v. 21 software. Several models were adjusted using various sets of information layers coming from the opinion survey and the field observations.

\section{RESULTS}

\subsection{Characteristics affecting actual travel speeds on the collector streets}

3.1.1 Field surveys: data description

During the field surveys, detailed data were collected on eighty street sections. Table 1 presents estimates of the traffic volumes and travel speed indicators on the study sections, by road layout types. As evident, multi-lane dual-carriageway streets are characterized by highest vehicle traffic volumes, followed by single-carriageway and two-lane one-way streets and then by single-lane dual-carriageway streets, while one-lane one-way roads have the lowest vehicle volumes.

As to the level of pedestrian activity on the street, it was quite similar on all street types, with an hourly average in the range of 450-550 walking pedestrians (on both sidewalks). On all the street types, we observed pedestrians who crossed the street not at the arranged crosswalks; the share of such pedestrians was, on average, between $14 \%-25 \%$ related to the number of pedestrians walking on the sidewalks. Simultaneously, $2 \%-15 \%$ of pedestrians crossed at the marked crosswalks relative to the number of pedestrians who walked on the sidewalks ${ }^{1}$. The total pedestrian crossing activity on the street can be seen in the sum of both indicators which lies in the range of $23 \%-38 \%$. In can also be noted (see Table 1 ) that on all street types, the amount of pedestrians crossing outside the arranged crosswalks was higher than at the marked crosswalks. The travel speeds were generally not high on all street types, with average values of the mean and the $85^{\text {th }}$ percentile speeds, in the street groups, below the speed limit; however, vehicles travelling at speeds over the speed limit were observed in all the street groups. The highest speeds, as expected, were measured on multi-lane dual-carriageway streets (see Table 1).

Table 2 presents descriptive statistics of the study sections according to various road characteristics. For further analyses, some characteristics were generalized into a reduced number of categories, related to the detailed original data that were defined during the field surveys; such generalized characteristics are indicated in Table 2 . In addition, vehicle and pedestrian exposure indicators were converted into uniform ranges of categories.

As indicated in Sec.2, travel speeds on the street sections were characterized by three indicators: the mean speed, the $85^{\text {th }}$ percentile speed and the percentage of drivers travelling above the speed limit. An examination of the correlations between the speed indicators revealed that, for each layout type, the correlation between the values of the mean and the $85^{\text {th }}$ percentile speeds was strong, with Pearson correlation coefficients of 0.89-0.99 ( $p<0.001)$. Similarly, the percentage of vehicles above the speed limit was strongly correlated with the two other speed

\footnotetext{
1 As introduced in Sec.2.1, three measures of pedestrian activity were estimated for each street: the number of pedestrians passing on the sidewalks; the number of pedestrians who crossed at the arranged crosswalks and the number of pedestrians who crossed without crosswalks. The three measures were counted simultaneously in the same time frame and converted into hourly figures. The number of pedestrians counted on the sidewalks reflected the level of pedestrian activity on the street. To characterize the scope of pedestrian crossing activity we estimated two ratios: between the amount of pedestrians who crossed outside the marked crosswalks or at the marked crosswalks and the number of walking pedestrians on the sidewalks. Both values are given as percentages in Table 1.
} 
Table 1. Estimates of traffic volumes and travel speed indicators on the study sections.

\begin{tabular}{|c|c|c|c|c|c|c|c|c|}
\hline $\begin{array}{l}\text { Road layout } \\
\text { type } \\
\text { (No of } \\
\text { sections) }\end{array}$ & $\begin{array}{l}\text { Estimates } \\
\text { in the } \\
\text { section } \\
\text { groups }\end{array}$ & $\begin{array}{l}\text { Hourly } \\
\text { vehicle } \\
\text { traffic, } \\
\text { vehicles }\end{array}$ & $\begin{array}{l}\text { Hourly } \\
\text { number of } \\
\text { pedestrians } \\
\text { on the } \\
\text { sidewalks }\end{array}$ & $\begin{array}{l}\text { Percent of } \\
\text { pedestrians } \\
\text { who crossed } \\
\text { at the } \\
\text { crosswalks* }\end{array}$ & $\begin{array}{l}\text { Percent of } \\
\text { pedestrians } \\
\text { who crossed } \\
\text { not at the } \\
\text { crosswalks** }\end{array}$ & $\begin{array}{l}\text { Mean } \\
\text { vehicle } \\
\text { speed, } \\
\text { km/h }\end{array}$ & $\begin{array}{l}85 \text { th } \\
\text { percentile } \\
\text { vehicle } \\
\text { speed, } \\
\text { km/h }\end{array}$ & $\begin{array}{l}\text { Percent of } \\
\text { vehicles } \\
\text { over the } \\
\text { speed limit }\end{array}$ \\
\hline \multirow{2}{*}{$\begin{array}{l}\text { Multi-lane dual- } \\
\text { carriageway (30) }\end{array}$} & Average & 1279 & 555 & 9 & 14 & 43.9 & 50.7 & 21.8 \\
\hline & S.d. & 378 & 180 & 14 & 11 & 5.7 & 6.5 & 20.7 \\
\hline \multirow{2}{*}{$\begin{array}{l}\text { Single-lane dual- } \\
\text { carriageway (9) }\end{array}$} & Average & 659 & 539 & 15 & 23 & 35.7 & 42.7 & 4.5 \\
\hline & S.d. & 100 & 161 & 16 & 17 & 4.9 & 5.6 & 7.3 \\
\hline \multirow{2}{*}{$\begin{array}{l}\text { Single- } \\
\text { carriageway (19) }\end{array}$} & Average & 724 & 449 & 7 & 25 & 34.4 & 40.2 & 4.9 \\
\hline & S.d. & 321 & 223 & 15 & 17 & 6.0 & 6.8 & 8.0 \\
\hline \multirow{2}{*}{$\begin{array}{l}\text { Two-lane one- } \\
\text { way (10) }\end{array}$} & Average & 729 & 496 & 5 & 18 & 34.8 & 41.0 & 1.3 \\
\hline & S.d. & 157 & 239 & 8 & 11 & 3.8 & 4.4 & 1.7 \\
\hline \multirow{2}{*}{$\begin{array}{l}\text { One-lane one- } \\
\text { way (12) }\end{array}$} & Average & 442 & 491 & 2 & 21 & 31.6 & 37.3 & 0.6 \\
\hline & S.d. & 166 & 187 & 3 & 13 & 4.3 & 4.8 & 1.9 \\
\hline
\end{tabular}

* Estimated as a ratio between the amount of pedestrians who crossed at the marked crosswalks and the number of pedestrians on the sidewalks. ** Estimated as a ratio between the amount of pedestrians who crossed not at the marked crosswalks and the number of pedestrians on the sidewalks.

indicators, on most layout types (except for one-way streets where the shares of vehicles over the speed limits were very low), with correlation coefficients of 0.79-0.94 $(\mathrm{p}<0.001)$. Thus, for the development of explanatory models for actual travel speeds we applied the mean speed values.

\subsubsection{Multivariate models}

At the initial step of the analysis, we examined the number of road layout types and the number of exposure indicators, to be applied in the models. For this, we developed multivariate regression models using all the potential explanatory variables, in four variants: with 5 or 4 layout types, with 3 or 4 exposure variables. Five layout types are presented in Table 2, four types are received when one-way streets (types 1-2) are considered together. Four exposure variables include: hourly vehicle traffic, hourly number of walking pedestrians, number of pedestrians who crossed at the arranged crosswalks and the number of those who crossed not at the crosswalks, while three exposure variables include total vehicle and pedestrian numbers and a total (combined) number of pedestrians that crossed the street. In all four preliminary models, we found the same significant (or close to significant) variables such as: layout type, presence of attractions, types of intersections, vehicle traffic and pedestrian traffic, and a similar level of the quality of fit, i.e. $62 \%-64 \%$ of variance explained. Thus, for the development of explanatory models we selected two variants: (a) a minimum set, with 4 layout types and 3 exposure variables, and (b) a maximum set, with 5 layout types and 4 exposure variables.

Table 3 presents the explanatory models fitted to actual travel speeds on the study sections, on the main step of the analysis, using two variants of the layout/ exposure variables as well as other road characteristics. One can note that both models are significant and very close according to the variance explained (65\%-66\%) and the explanatory variables selected. The models show that actual travel speeds on the collector streets are influenced by the road layout, where dual-carriageway roads are associated with higher travel speeds related to single-carriageway roads, and the latter - with higher speeds related to one-way roads. Similarly, streets with higher vehicle volumes tend to higher speeds. On the contrary, higher pedestrian activity and higher presence of commercial frontage on the street lead to lower speeds. In addition, street sections with un-signalized intersections at their ends are associated with lower speeds compared to those with signalized intersections.

Furthermore, to delve into the impact of the street characteristics on actual travel speeds, another explanatory model was adjusted, which did not use the data on the total vehicle and pedestrian volumes on the street and on the road layouts but used other variables - Table 4. This model has lower explained 
Table 2. Descriptive statistics of the study sections according to road characteristics.

\begin{tabular}{|c|c|}
\hline Road characteristics & Distribution of sections according to categories, \% \\
\hline Layout type & $\begin{array}{l}\text { [1] One-lane one-way (15\%), [2] two-lane one-way (12\%), [3] two-lane single- } \\
\text { carriageway }(24 \%),[4] \text { single-lane dual-carriageway }(11 \%), \text { [5] multi-lane dual- } \\
\text { carriageway (38\%) }\end{array}$ \\
\hline Lane width & [2] Wide (38\%), [1] medium (45\%), [0] small (17\%) \\
\hline Presence of visual narrowing* & [1] Low (40\%), [2] high (60\%) \\
\hline Median's (un)transparency & $\begin{array}{l}\text { [0] No median (51\%), [1] median without visual intrusions (24\%), [2] median with } \\
\text { visual intrusions (25\%) }\end{array}$ \\
\hline $\begin{array}{l}\text { Presence of pedestrian attractions } \\
\text { (commercial frontage)* }\end{array}$ & [1] Low (36\%), [2] high (64\%) \\
\hline Visibility distance for vehicles & [1] Full (86\%), [0] moderate (14\%), short (0\%) \\
\hline Parking configuration* & $\begin{array}{l}\text { [0] No parking }(9 \%),[1] \text { on one side of the street }(18 \%),[2] \text { parallel on both sides } \\
(52 \%),[3] \text { on both sides, with a diagonal parking }(21 \%)\end{array}$ \\
\hline Presence of bus stops & [1] Yes (59\%), [2] no (41\%) \\
\hline Presence of pedestrian crosswalks & [1] Yes (39\%), [0] no (61\%) \\
\hline $\begin{array}{l}\text { Types of intersections at the section's } \\
\text { ends }\end{array}$ & $\begin{array}{l}\text { [1] Signalized intersections on both sides ( } 30 \%) \text {, [2] signalized intersection on one } \\
\text { side }(37 \%), \text { [3] un-signalized intersections on both sides (33\%) }\end{array}$ \\
\hline Hourly vehicle traffic, vehicles & $\begin{array}{l}\text { [1] 200-400 (10\%), [2] 400-600 (20\%), [3] 600-800 (21\%), [4] 800-1000 (16\%), } \\
\text { [5] 1000-1200 (11\%), [6] 1200-1400 (6\%), [7] 1400-1600 (6\%), [8] over } 1600(9 \%)\end{array}$ \\
\hline $\begin{array}{l}\text { Hourly number of pedestrians on the } \\
\text { sidewalks }\end{array}$ & $\begin{array}{l}\text { [1] } 100-200(7.5 \%),[2] 200-300(16 \%),[3] 300-400(7.5 \%), \text { [4] } 400-500(11 \%), \\
\text { [5] 500-600 (14\%), [6] 600-700 (15\%), [7] over } 700(29 \%)\end{array}$ \\
\hline $\begin{array}{l}\text { Hourly number of pedestrians who } \\
\text { crossed the section not at the crosswalks }\end{array}$ & $\begin{array}{l}\text { [1] below } 25(15 \%), \text { [2] 25-50 (22.5\%), [3] 50-75 (20\%), [4] 75-100 (9\%), [5] 100-125 } \\
(9 \%),[6] 125-150(7.5 \%),[7] 150-200(6 \%),[8] 200-300 \text { (6\%), [9] over } 300(5 \%)\end{array}$ \\
\hline
\end{tabular}

* A generalization into a reduced number of categories was applied related to the original data collection.

variance than previous models $(45 \%)$ but points to the effect of additional street characteristics. It shows that actual travel speeds decrease with an increase in the presence of commercial frontage on the street (like in previous models) but also with higher presence of visual narrowing on the street and when more pedestrians cross the street not at the marked crosswalks. Contrary to expectations, the model indicates that higher speeds are expected on sections with more visual intrusions on the median (related to those with no median) and on sections with presence of bus stops (related to those without the stops). It seems that both latter variables serve as moderators of the "road layout", since closed medians (e.g. with pedestrian fences) and presence of bus stops are more typical for multi-lane dual-carriageway streets, which are associated with higher speeds. Other layout types and, particularly, one-way one-lane streets, more rarely include bus stops, and are characterized by lower speeds. Hence, the characteristics of medians and of the bus stops' presence should not be treated as separate factors affecting actual travel speeds, while the use of road layout type is preferable in this sense.

\subsection{Characteristics affecting appropriate speeds on the collector streets, according to drivers' opinions}

\subsubsection{Drivers' survey: data description}

The drivers' survey was conducted as designed and had a $36 \%$ response rate. Responses of 200 participants were received and converted into the data on 800 street sections. For each section, the data included speed limits and the appropriate speeds as reported by drivers in the opinion survey, background characteristics of the respondents and road characteristics, which were added from the field surveys.

As explained in Sec.2, based on the drivers' responses to the set of safety statements of the questionnaire and using a cluster analysis, three groups of drivers were identified according to their attitudes. Table 5 presents the average values of agreement with various statements in the drivers' groups. One can note that 
group 2 stated the most careful behaviors in the urban environment with an inclination to lower travel speeds; group 3 expressed a tendency to higher speeds in various traffic situations; group 1 included drivers with an intermediate position, between the two other groups. Moreover, the appropriate speeds reported by the drivers were in line with the manner of behavior that was reflected in their statements, where group 2 consistently suggested the lowest speeds for various road layouts and group 3 - the highest speeds, see last columns in
Table 5 (with the mean values of appropriate speeds in various drivers' groups). Belonging to drivers' groups was added to the drivers' characteristics.

Table 6 provides descriptive statistics of the street sections based on the drivers' survey, including the variables' definition for further modeling. To note, the splits of the responses according to drivers' age groups and socio-economic clusters of the cities, in the survey, were close to the corresponding distributions in the general drivers' population of the country.

Table 3. Explanatory models fitted to actual travel speeds, with road layout and exposure variables.

\begin{tabular}{|c|c|c|c|c|c|c|c|c|}
\hline \multirow[t]{3}{*}{ Variables } & \multicolumn{4}{|c|}{ Model a } & \multicolumn{4}{|c|}{ Model b } \\
\hline & \multicolumn{2}{|c|}{$\begin{array}{l}\text { Unstandardized } \\
\text { Coefficients }\end{array}$} & \multirow[t]{2}{*}{$\mathbf{t}$} & \multirow[t]{2}{*}{ Sig. } & \multicolumn{2}{|c|}{$\begin{array}{l}\text { Unstandardized } \\
\text { Coefficients }\end{array}$} & \multirow[t]{2}{*}{$\mathbf{t}$} & \multirow[t]{2}{*}{ Sig. } \\
\hline & B & $\begin{array}{l}\text { Std. } \\
\text { Error }\end{array}$ & & & B & $\begin{array}{l}\text { Std. } \\
\text { Error }\end{array}$ & & \\
\hline Constant & 41.127 & 2.686 & 15.310 & 0.000 & 41.072 & 2.713 & 15.141 & 0.000 \\
\hline Layout type & 2.901 & 0.516 & 5.617 & 0.000 & 2.423 & 0.441 & 5.491 & 0.000 \\
\hline $\begin{array}{l}\text { Hourly number of pedestrians on the } \\
\text { sidewalks }\end{array}$ & -1.316 & 0.256 & -5.139 & 0.000 & -1.252 & 0.258 & -4.857 & 0.000 \\
\hline Presence of pedestrian attractions & -3.269 & 1.062 & -3.077 & 0.003 & -3.681 & 1.069 & -3.444 & 0.001 \\
\hline Hourly vehicle traffic & 0.841 & 0.310 & 2.712 & 0.008 & 0.823 & 0.316 & 2.600 & 0.011 \\
\hline Types of intersections at the section's ends & -1.305 & 0.649 & -2.009 & 0.048 & -1.463 & 0.649 & -2.253 & 0.027 \\
\hline
\end{tabular}

Notes: See variable definitions in Table 2 (categories were used for modeling). Model $a$ - with 4 layout types and 3 exposure variables; $\mathrm{F}_{5,74}=30.94, \mathrm{p}<0.0001$; adjusted $\mathrm{R}^{2}=65.5 \%$. Model $b$ - with 5 layout types and 4 exposure variables; $\mathrm{F}_{5,74}=30.33$, $\mathrm{p}<0.0001 ;$ adjusted $\mathrm{R}^{2}=65.0 \%$.

Table 4. Explanatory model fitted to actual travel speeds, without using road layout and exposure variables (Model c).

\begin{tabular}{|c|c|c|c|c|}
\hline \multirow[t]{2}{*}{ Variables } & \multicolumn{2}{|c|}{$\begin{array}{l}\text { Unstandardized } \\
\text { Coefficients }\end{array}$} & \multirow[t]{2}{*}{$\mathbf{t}$} & \multirow[t]{2}{*}{ Sig. } \\
\hline & B & $\begin{array}{l}\text { Std. } \\
\text { Error }\end{array}$ & & \\
\hline Constant & 52.935 & 3.326 & 15.915 & 0.000 \\
\hline Median's (un)transparency & 3.157 & 0.760 & 4.154 & 0.000 \\
\hline Presence of pedestrian attractions & -3.677 & 1.309 & -2.808 & 0.006 \\
\hline Presence of visual narrowing & -2.823 & 1.293 & -2.183 & 0.032 \\
\hline Hourly number of pedestrians who crossed the section not at the crosswalks & -0.695 & 0.270 & -2.579 & 0.012 \\
\hline Presence of bus stops & -3.066 & 1.344 & -2.282 & 0.025 \\
\hline
\end{tabular}

See variable definitions in Table 2 (categories were used for modeling). Model statistics: $\mathrm{F}_{5,74}=13.87$, $\mathrm{p}<0.0001$; adjusted $\mathrm{R}^{2}=44.9 \%$. 
Table 5. Homogeneous groups of drivers according to their responses to safety statements of the questionnaire.

\begin{tabular}{|c|c|c|c|c|c|c|c|c|}
\hline \multirow[b]{2}{*}{$\begin{array}{l}\text { Drivers' } \\
\text { group } \\
\text { (number of } \\
\text { respondents) }\end{array}$} & \multicolumn{5}{|c|}{ Average values of agreement* with statement (sd) } & \multicolumn{3}{|c|}{$\begin{array}{l}\text { Mean values of (reported) appropriate } \\
\text { speeds for road layouts, } \mathrm{km} / \mathrm{h} \text { (sd) }\end{array}$} \\
\hline & $\begin{array}{l}\text { In city } \\
\text { center } \\
\text { I always } \\
\text { drive at } \\
\text { speed below } \\
50 \mathrm{~km} / \mathrm{h}\end{array}$ & $\begin{array}{l}\text { On street } \\
\text { with many } \\
\text { crossing } \\
\text { pedestrians } \\
\text { I slow down }\end{array}$ & $\begin{array}{l}\text { On street } \\
\text { with many } \\
\text { parked } \\
\text { vehicles } \\
\text { I slow } \\
\text { down }\end{array}$ & $\begin{array}{l}\text { On street } \\
\text { with } \\
\text { signalized } \\
\text { junctions } \\
\text { I speed up }\end{array}$ & $\begin{array}{l}\text { On street } \\
\text { with many } \\
\text { travel } \\
\text { lanes } \\
\text { I speed up }\end{array}$ & $\begin{array}{l}\text { Single- } \\
\text { lane dual- } \\
\text { carriageway }\end{array}$ & $\begin{array}{l}\text { Multi-lane } \\
\text { dual- } \\
\text { carriageway }\end{array}$ & $\begin{array}{l}\text { Single- } \\
\text { carriageway }\end{array}$ \\
\hline $1(104)$ & $4.7(0.5)$ & $4.9(0.3)$ & $4.5(0.7)$ & $2.7(1.1)$ & $4.1(0.6)$ & $41.8(10.1)$ & $48.3(9.2)$ & $41.5(11.5)$ \\
\hline $2(50)$ & $4.5(0.8)$ & $5.0(0.2)$ & $4.8(0.4)$ & $1.4(0.6)$ & $1.9(0.8)$ & $39.5(10.1)$ & $44.4(10.3)$ & $39.5(9.0)$ \\
\hline $3(46)$ & $2.5(0.8)$ & $4.4(0.9)$ & $3.6(1.0)$ & $2.5(0.9)$ & $3.8(0.8)$ & $44.8(12.2)$ & $54.2(9.8)$ & $46.4(11.7)$ \\
\hline
\end{tabular}

* On scale 1-5, from "fully disagree" to "fully agree".

\section{Table 6. Descriptive statistics of the street sections based on the drivers' survey.}

\section{Characteristics of street sections/ respondent drivers ${ }^{\#}$ \\ Categories: [number] and meaning, and distribution of responses according to categories (\%)}

Road layout type (baseline - D)

Socio-economic cluster of the city*

Driver's gender (baseline - female)

Driver's age group*

Driving experience of the respondent, years*

Annual kilometrage of the respondent*

Familiarity with the area (baseline - casual)

Lane width*

Presence of visual narrowing (baseline - high)

Median's (un)transparency*

Presence of pedestrian attractions (baseline - high)

Parking configuration*

Belonging to drivers' groups according to safety statements (baseline - group 3)

\begin{tabular}{llllll}
\hline Speed variables $^{\#}$ & Mean & Median & S.d. & Min & Max \\
\hline Appropriate speed (reported by drivers), km/h & 43.1 & 40 & 11.2 & 10 & 90 \\
Speed limit (reported by drivers), km/h & 47.5 & 50 & 8.4 & 20 & 90 \\
Mean travel speed (observed), $\mathrm{km} / \mathrm{h}$ & 36.2 & 35.1 & 6.9 & 24.9 & 58.6 \\
\hline
\end{tabular}

[A] Single-lane dual-carriageway (25\%), [B] multi-lane dual-carriageway (25\%), [C] single-carriageway (25\%), [D] one-way (25\%)

[1] Low (20\%), [2] medium (30\%), [3] high (30\%), [4] very high (20\%)

[1] Male (59\%), [0] female (41\%)

[1] 17-34 (38\%), [2] 35-54 (39\%), [3] 55+ (23\%)

[1] Up to 5 (14\%), [2] 6-10 (13\%), [3] over 10 (73\%)

[1] Below 10,000 km (38\%), [2] 10,000-20,000 (34\%),

[3] over 20,000 km (28\%)

[1] Casual (17\%), [2] lives in the area (34\%), [3] works in the area (49\%)

[0] Small (17\%), [1] medium (43\%), [2] wide (40\%)

[0] High (65\%), [1] low (35\%)

[0] No median (50\%), [1] median without visual intrusions (20.5\%),

[2] median with visual intrusions (29.5\%)

[0] High (73\%), [1] low (27\%)

[0] No parking (2\%), [1] on one side of the street (17\%), [2] parallel on both sides (52\%), [3] on both sides, with a diagonal parking (29\%)

[0] Group 3 (23\%), [1] group 1 (52\%), [2] group 2 (25\%)

\# Based on 800 responses matched with road characteristics. *Ordinal variables 
Table 7. Speed limits and appropriate speeds on four major layout types, as reported by drivers ( $N=200)$.

\begin{tabular}{l|cccc|cccc}
\hline \multirow{2}{*}{ Layout type } & \multicolumn{4}{|c|}{ Speed limit, $\mathbf{k m} / \mathbf{h}$} & \multicolumn{4}{c}{ Appropriate speed, $\mathbf{k m} / \mathbf{h}$} \\
\cline { 2 - 9 } & Average & S.d. & Min & Max & Average & S.d. & Min & Max \\
\hline A Single-lane dual-carriageway & 47.1 & 7.3 & 20 & 70 & 42.0 & 10.6 & 10 & 70 \\
B Multi-lane dual-carriageway & 50.9 & 7.8 & 20 & 80 & 48.9 & 10.3 & 20 & 70 \\
C Single-carriageway & 46.9 & 8.8 & 20 & 90 & 42.3 & 11.4 & 15 & 90 \\
D One-way & 45.2 & 8.3 & 25 & 70 & 39.6 & 10.7 & 10 & 60 \\
\hline
\end{tabular}

Table 8. Explanatory models fitted to the appropriate speeds, using various information layers.

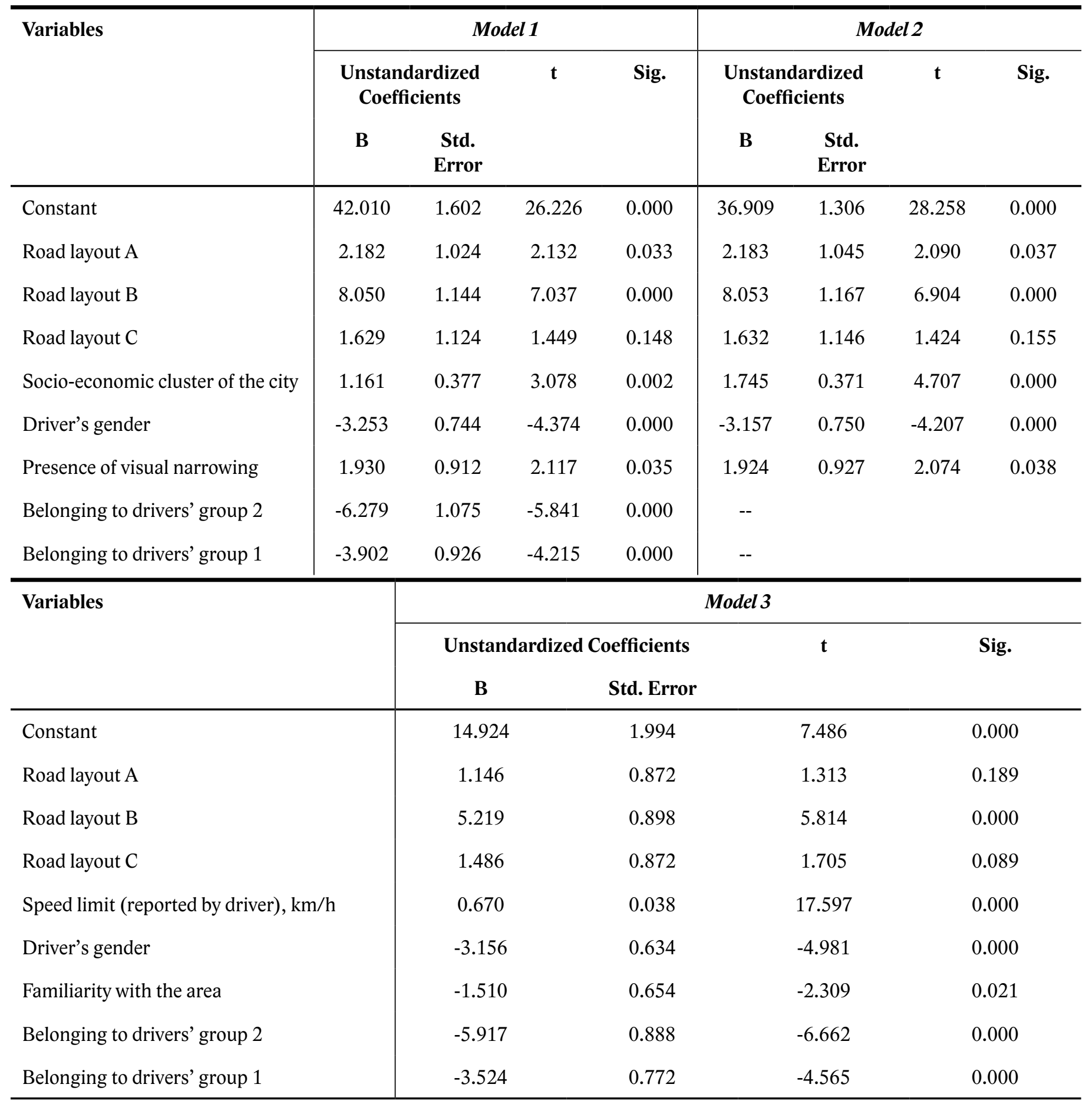

Notes: See variable definitions in Table 6. Model 1: $\mathrm{F}_{8,795}=21.35$, $\mathrm{p}<0.0001$; adjusted $\mathrm{R}^{2}=16.9 \%$. Model 2: $\mathrm{F}_{6,797}=21.77, \mathrm{p}<0.0001$; adjusted $\mathrm{R}^{2}=13.4 \%$. Model 3: $\mathrm{F}_{8,795}=66.19, \mathrm{p}<0.0001$; adjusted $\mathrm{R}^{2}=39.4 \%$. 


\subsubsection{Differences between the reported speed limits and appropriate speeds}

Table 7 presents the speed limits and the speeds appropriate for travel on the four major layout types, as reported by drivers. A paired examination of differences between the speed limit and the appropriate speed values indicated a significant difference $(\mathrm{p}<0.01)$, for all layout types, where the reported speed limits were systematically higher than the suggested appropriate speeds. (A similar result was received in a detailed comparison of the speed limits and the appropriate speeds, across the representative road layouts that were developed for the drivers' survey.)

The difference between the mean values of the two measures was higher for moderate road layouts (single-lane, single-carriageway, one-way) and lower - for a wider road layout (multi-lane dual-carriageway): about 5 and $2 \mathrm{~km} / \mathrm{h}$, respectively. A remarkable finding of this step was that for moderate road layouts a collective opinion of the drivers was that the appropriate travel speed should be around $40 \mathrm{~km} / \mathrm{h}$, i.e. lower than the existing speed limit $(50 \mathrm{~km} / \mathrm{h})$.

\subsubsection{Multivariate models}

Table 8 shows the explanatory models fitted to the appropriate travel speeds on the street sections, using various information layers, as follows:

- Model 1 - using road layout types, driver characteristics, driver groups and road characteristics;

- Model 2 - the same as model 1 but without driver groups;

- Model 3 - the same as model 1 plus the speed limit values that were reported by drivers.

All the models were significant while the explanatory power was higher for model 3 . All the models showed that layout type affects the selection of the appropriate speed, where the highest speeds are associated with type B (multi-lane dual-carriageway streets), lower speeds - with types A, C (single-lane dual-carriageway and single-carriageway streets) and the lowest ones - with type D (one-way roads). Low visual narrowing of the street leads to the selection of higher speeds (similarly to the previous findings - see Sec.3.1). In the cities with a higher socio-economic level the drivers tend to prefer higher appropriate speeds. This may reflect the paradox that better maintained roads (in more affluent local authorities) may "invite" higher speeds (once the road does not include traffic calming measures). However, when the driver lives in the area, he/she selects a lower appropriate speed.

The groups of drivers with attitudes reflecting safer behaviors in urban areas selected lower appropriate speeds. Somewhat unexpectedly, males preferred lower speeds compared to females. In addition, in model 3, reporting higher speed limit by the driver was associated with selecting higher appropriate speeds, thus indicating a consensus in the way the driver "perceives" the street view with regard to both speed indicators.

Finally, the layer of actual travel speeds was added to the section characteristics and the regression models were re-fitted. The results were close to those presented by models 1-3 in Table 8, while mean travel speed appeared among the explanatory variables for the "appropriate" speed and showed a direct link between the two variables. In addition, the value of the variance explained by models $1-2$ with actual travel speeds (adjusted $\mathrm{R}^{2}$ ) was slightly higher (by about $2 \%$ ) than for the original models in Table 8.

\section{DISCUSSION AND CONCLUSIONS}

This study examined the speed perception by drivers on collector urban roads in Israel, as reflected in their actual travel speeds and in the "appropriate" speeds reported by drivers. The results indicated a consistency between the actual and the reported speeds, on various street sections. Road layout was found to be the most influential characteristic for speed selection. Multi-lane dual-carriageway roads are characterized by the highest actual and reported speeds, where lower speeds are attributed to single-lane dual-carriageway and single-carriageway roads, and the lowest one - to one-way roads. Hence, a more constricted street layout, with one travel lane per direction or one-way traffic, is perceived by drivers as moderating speeds and leads to lower actual speeds, compared to a wider layout. This result is in line with previous research which found that narrow roadways led to lower travel speeds (Edquist et al., 2009; York et al., 2007; Charlton et al., 2010; Bassani et al., 2014), yet, the impact of types of urban road layouts was not explicitly reported in the past.

Additionally, higher pedestrian activity on the street and higher visual narrowing are associated with lower actual and/or perceived speeds, as was 
also reported by previous research (Fitzpatrick et al., 2005; Milot, 2008; Ivan et al., 2009; Bassani et al., 2014). Among other road characteristics leading to lower travel speeds the current study indicated: higher presence of commercial frontage on the street and the presence of un-signalized intersections as opposed to signalized junctions. Conversely, the study did not exhibit the impact on speeds of such characteristics as: lane width, parking configuration or visibility distance that were indicated by previous research (Fitzpatrick et al., 2005; York et al., 2007; Edquist et al., 2009; Charlton et al., 2010). The effects of the presence of bus stops or a median were shown in some results, however, they apparently reflected the impact of the road layout.

The study showed a direct link between the actual and reported speeds on the same urban roads thus supporting the possibility to rely on drivers' perception in future research of road design. The reported speeds were mostly dependent on the road view (the layout) but also on driver's personal characteristics and attitudes, and the socio-economic level of the city. Such a combination of objective and personal factors is expected (Shinar, 2017), however, the study provided the details, which can be accounted for in further developments of the urban environment.

Unlike the findings from a national speed survey (e.g. Gitelman, 2014), the study did not observe high shares of vehicles travelling above the speed limits on the collector roads; this difference may stem from the "observation window" selected by the current study, which covered the busiest hours of urban activities. An important finding of this study was that for moderate street layouts, the drivers believed that the appropriate speed should be around $40 \mathrm{~km} / \mathrm{h}$, i.e. below the existing speed limit $(50 \mathrm{~km} / \mathrm{h})$. Together with other indications seen in the results, e.g. a preference for lower speeds when the driver lives or works in the area; a need for safer driving behavior in urban areas as expressed in drivers' attitudes, it shows a rising awareness of road safety concerns in the drivers' population of the country.

In summary, the study demonstrated that Israeli drivers are aware of the need for lowering travel speeds on urban streets and, particularly, in the presence of pedestrians, which is in line with advanced safety concepts (ITF, 2016; European Commission, 2018). Motorists are capable of identifying the characteristics of urban streets conveying the possibility of travel at a higher or lower speed. The road characteristics that were found to affect the speed selec- tion by the drivers may be applicable for attaining targeted travel speeds in urban areas (OECD, 2006; Ministry of Transport, 2010). In particular, among the measures lowering travel speeds on the collector streets, can be suggested: moderating road layout, higher visual narrowing of the street, increasing the amount of pedestrian attractions on the street. Traffic calming measures may provide additional safety benefits for pedestrians (Gitelman et al., 2012; European Commission, 2018), however, their implications on traffic and road user behaviors on collector roads should be evaluated by empirical research.

Acknowledgements: This study was commissioned by the National Road Safety Authority of Israel.

\section{REFERENCES}

Aarts, L., and van Schagen, I.N.L.G. (2006). Driving speed and the risk of road crashes: a review. Accident Analysis \& Prevention, 38(2), 215-224.

Adminaité-Fodor, D., Jost, G. (2019). Reducing speeding in Europe. PIN Flash Report 36. European Transport Safety Council, Brussels.

Breene, J. (2018). Preparatory work for an EU road safety strategy 2020-2030. Written by J. Breene Consulting, SWOV and Loughborough University. European Commission.

CBS (2011). The socio-economic index of local authorities. Central Bureau of Statistics, Jerusalem, Israel.

Charlton, S. G., Mackie, H. W., Baa, P. H., Hay, K., Menezes, M. and Dixson, C. (2010). Using endemic road features to create self-explaining roads and reduce vehicle speeds. Accident Analysis \& Prevention, 42, 1989-1998.

Edquist, J., Rudin-Brown, C.M., Lenne, M.G. (2009). Road Design Factors and Their Interactions with Speed and Speed Limits. Monash University Accident Research Centre, Australia.

Eiksund, S. (2009). A geographical perspective on driving attitudes and behaviour among young adults in urban and rural Norway. Safety Science, 47, 529-536.

Elvik, R., Vadeby, A., Hels, T., van Schagen, I. (2019). Updated estimates of the relationship between speed and road safety at the aggregate and individual levels. Accident Analysis and Prevention, $123,114-122$.

European Commission (2018). Speed and Speed Management. European Commission, Directorate General for Transport, February 2018.

Fitzpatrick, K., Miaou, S.-P., Brewer, M. et al. (2005). Exploration of the relationship between operating speed and roadway features on tangent sections. Journal of Transportation Engineering, 131(4), 261-269. 
Gitelman, V. (2014). Establishing a National system for monitoring safety performance indicators in Israel; An example of a National speed survey. In Proceedings of International Conference Transport Safety Performance Indicators, Belgrade, Serbia, March 2014 (pp. 27-49).

Gitelman, V., Balasha, D., Carmel, R., Hendel, L., Pesahov, F. (2012). Characterization of pedestrian accidents and an examination of infrastructure measures to improve pedestrian safety in Israel. Accident Analysis and Prevention, 44, 63-73.

Gitelman, V., Pesahov, F., Carmel, R., Bekhor, S. (2016). The identification of infrastructure characteristics influencing travel speeds on single-carriageway roads to promote self-explaining roads. Transportation Research Procedia, 14 (2016), 4160-4169.

Gitelman, V., Doveh, E., Balasha, D. (2018). Safety evaluation of urban streets with mixed land use: examining the role of early stage of planning. In M. Pezzagno and M. Tira (eds.), Town and Infrastructure Planning for Safety and Urban Quality (pp. 115-121). CRC Press.

Guidelines (2009). Guidelines for design of urban streets - the street space. Ministry of Transport and Ministry of Housing, Jerusalem, Israel.

ITF (2016). Zero road deaths and serious injuries: Leading a paradigm shift to a Safe System. International Transport Forum, OECD Publishing, Paris.

Ivan, J.N., Garrick, N.W., Hanson, G. (2009). Designing roads that guide drivers to choose safer speeds. Report No. JHR 09-321. Joint Highway Research Advisory Council of the University of Connecticut and the Connecticut Department of Transportation, USA.

Johnson, R.A. \& Wichern, D.W. (2002). Applied multivariate statistical analysis. New Jersey: Pearson Education

Lahausse, J.A., Van Nes, N., Fildes, B.N., Keall, M.D. (2010). Attitudes towards current and lowered speed limits in Australia. Accident Analysis and Prevention, 42, 2108-2116.

Milot, M. (2008). Does Modern Urban Road Layout Improve Road Safety: Which Assessment? In Proceedings of European Transport Conference, Leeuwenhorst, The Netherlands. Association for European Transport and Contributors.

Ministry of Transport (2010). Guidelines for determining speeds on the road network. Jerusalem, Israel.

OECD (2006). Speed management. Organization for Economic Co-operation and Development, Paris

Preston, C.C., Colman, A.M. (2000). Optimal number of response categories in rating scales: reliability, validity, discriminating power, and respondent preferences. Acta Psychologica, 104, 1-15.

Raudenbush, S.W. (2004). HLM 6: Hierarchical linear and nonlinear modeling. Scientific Software International.

Shinar, D. (2017). Traffic Safety and Human Behavior. Second edition, Emerald Group Publishing.

Troitsky, A. (2018). National survey of travel speeds in Israel 2017. National Road Safety Authority, Israel.
Van der Horst, R., Kaptein, N. (1996). Self-Explaining Roads. Transportation Research Record, 1550, 30-36.

Weller, G., Schlag, B., Friedel, T., Rammin, C.(2008). Behaviourally relevant road categorisation: A step towards self-explaining rural roads. Accident Analysis and Prevention, 40, 1581-1588.

York, I., Bradbury, A., Reid, S., Ewings, T., and Paradise, R. (2007). The manual for streets: evidence and research. TRL Report TRL661. Transport Research Laboratory, UK. 